\title{
PROFIL URETRITIS GONOKOKUS DAN NON-GONOKOKUS PADA PRIA DI RSUP. PROF. DR. R.D. KANDOU MANADO PERIODE 2009 - 2011
}

\author{
${ }^{1}$ Yan D. P. Silalahi \\ ${ }^{2}$ Pieter L. Suling \\ ${ }^{2}$ Marlyn G. Kapantow
}

\author{
${ }^{1}$ Kandidat skripsi Fakultas Kedokteran Universitas Sam Ratulangi Manado \\ ${ }^{2}$ Bagian /SMF Kulit dan Kelamin RSUP Prof. Dr. R.D.Kandou Manado \\ Email: paruliansilalahiyandavid@yahoo.co.id
}

\begin{abstract}
Urethritis, an inflammation of the urethra, is divided into gonococcal urethritis and non-gonococcal urethritis. It is a venereal disease transmitted through sexual contact resulting in a complaint of pain sensation during urination. This was a descriptive retrospective study. Data were obtained from the registration of sexually transmitted infections from the Department of Dermatology and Venereal Diseases Prof Dr. R.D. Kandou Hospital Manado. The results showed that from 2009 until 2011 there were 82 male patients with urethritis; 56 patients $(68.5 \%)$ with gonococcal urethritis and 26 patients $(31.5 \%)$ with non-gonococcal urethritis. The highest number of patients (51 patients, $62 \%)$ were at the ages of 25-44 years. The most frequent patient jobs were civil employes (38 patients, $46.4 \%$ ), followed by students ( 10 patients, $12 \%$ ), and jobless ( 8 patients, $10 \%$ ). The most common sexual partners were female prostitutes (38 patients, $46.3 \%$ ). The most frequent complaint of gonococcal and non-gonococcal urethritis patients was pain sensation during urination (35 patients, $42.7 \%$ ). Conclusion: In this study, most male patients with gonococcal and non-gonococcal urethritis were at the ages of 25-44 years, worked as civil employees, and had sexual intercourse with female prostitutes. The most common complaint among them was pain sensation during urination
\end{abstract}

Keywords: urethritis, gonococcal, non-gonococcal, males

\begin{abstract}
Abstrak : Uretritis adalah peradangan pada uretra dan terbagi menjadi uretritis gonokokus dan non gonokokus. Penyakit ini tergolong pada infeksi menular seksual (IMS) dengan penularan melalui hubungan seksual dan keluhan berupa nyeri saat berkemih. Penelitian ini bersifat deskriptif retrospektif; data diambil dari buku register infeksi menular seksual Bagian Ilmu Penyakit Kulit dan Kelamin RSU Prof Dr. R.D. Kandou Manado. Hasil penelitian memperlihatkan dari 82 kasus laki-laki dengan uretritis gonokokus (UG) non gonokokus (UNG) tahun 2009-2011 terdapat 56 pasien (68,5\%) dengan UG dan 26 pasien $(31,5 \%)$ dengan UNG. Usia 25-44 tahun merupakan kelompok usia terbanyak yaitu 51 pasien $(62 \%)$. Jenis pekerjaan yang tersering untuk pasien UG dan UNG ialah pegawai sebanyak 38 orang (46,4\%). Pasangan seksual pasien uretritis gonokokus dan non gonokokus yang tersering ditemukan ialah wanita pekerja seksual (WPS) sebanyak 38 orang $(46,3 \%)$. Keluhan tersering pada pasien uretritis gonokokus dan non gonokokus ialah nyeri saat berkemih sebanyak 35 orang (42,7\%). Simpulan: Dalam penelitian ini, pasien laki-laki dengan uretritis gonokokus dan non gonokokus tersering pada kelompok usia 25-44 tahun, jenis pekerjaan pegawai, dan pasangan seksual terbanyak wanita pekerja seksual. Keluhan yang tersering dikemukakan ialah nyeri saat berkemih.
\end{abstract}

Kata kunci: uretritis, gonokokus, non-gonokokus, laki-laki 
Uretritis adalah peradangan uretra yang terbagi atas uretritis gonokokus (UG) dan uretritis non-gonokokus (UNG). Uretritis tergolong infeksi menular seksual (IMS) yang ditularkan melalui hubungan seksual dengan gejala disuria (nyeri saat berkemih). ${ }^{1}$ Data epidemiologi dari Kelompok Studi Infeksi Menular Seksual Indonesia (KSIMSI) tahun 2012 menemukan insidens UG di Manado tahun 2007-2011 sebesar $31 \%$, menempati urutan ke-2 di Indonesia Medan (26,3\%), Padang (33,3\%), Bandung (28,7\%), Semarang (23,8\%), Yogyakarta $(27,3 \%)$ dan Denpasar $(16,3 \%)$. UNG di Manado menempati urutan pertama bersama dengan Padang dan Surabaya. ${ }^{2}$

Kuman penyebab UG ialah Neisseria gonorrhoeae sedangkan kuman penyebab UNG ialah Chlamydia trachomatis dan Ureaplasma urealyticum. Transmisi kuman penyebab UG dan UNG melalui genitor-genital, ano-genital, dan oro-genital. Terjadinya infeksi tidak selalu harus melalui hubungan kelamin. Pada beberapa kasus infeksi dapat ditularkan melalui kontak langsung dengan alat-alat seperti handuk, termometer, dan sebagainya. ${ }^{3-6}$

Pada laki-laki, UG muncul sebagai uretritis akut dengan gejala keluarnya cairan (discharge) dari uretra disertai disuria. Gejala pada UNG ialah discharge uretra, disuria, poliuria, terasa gatal pada uretra, dan iritasi penis. ${ }^{7-9}$

Pada pengobatan UG dan UNG, semua pasangan seksual berisiko harus dinilai dan ditawarkan pengobatan serta menjaga kerahasiaan pasien. Cefixime dan ceftriaxone ialah sefalosporin generasi ketiga yang direkomendasikan sebagai terapi lini pertama untuk UG. Cefixime di- berikan per oral dalam dosis tunggal sedangkan ceftriaxone diberikan per injeksi intramuskular. Pada pengobatan UNG, azitromisin dan doksisiklin merupakan terapi lini pertama yang diberikan per oral. ${ }^{9}$

Pemahaman mengenai UG dan UNG pada laki-laki serta penanganan awal sangat dibutuhkan untuk mencegah komplikasi penyakit dan penularan lebih lanjut.

\section{METODE PENELITIAN}

Penelitian ini bersifat deskriptif retrospektif. Data diambil dari buku register penyakit menular seksual pasien laki-laki dengan UG dan UNG di Poliklinik Kulit dan Kelamin RSUP Prof. Dr. R.D. Kandou Manado.

Populasi mencakup seluruh pasien yang datang berobat ke Poliklinik Kulit dan Kelamin pada tahun 2009-2011 di Manado. Sampel yaitu semua pasien lakilaki yang menderita UG dan UNG yang berobat ke RSUP Prof. Dr. R.D. Kandou Manado selama periode 1 Januari 2009 30 Desember 2011. Variabel penelitian meliputi jenis penyakit, umur, pekerjaan, pasangan seksual, dan keluhan.

\section{HASIL PENELITIAN}

Dari data yang diambil dari buku register penyakit menular seksual pasien laki-laki dengan UG dan UNG yang berobat di Poliklinik Kulit dan Kelamin RSUP Prof. Dr. R.D. Kandou Manado pada tahun 2009-2011 diperoleh jumlah pasien uretritis total 82 orang: pasien UG 56 orang dan pasien UNG 26 orang (Tabel 1).

Tabel 1. Distribusi jenis penyakit.

\begin{tabular}{cccccc}
\hline Jenis penyakit & 2009 & 2010 & 2011 & Jumlah & $\%$ \\
\hline UG & $21(25,4 \%)$ & $19(23,1 \%)$ & $16(20 \%)$ & $\mathbf{5 6}$ & $\mathbf{6 8 , 5 \%}$ \\
UNG & $12(14,5 \%)$ & $5(6 \%)$ & $9(11 \%)$ & 26 & $31,5 \%$ \\
\hline Jumlah & 33 & 24 & 25 & 82 & \\
$(\%)$ & $39,9 \%$ & $29,1 \%$ & $31 \%$ & & $100 \%$ \\
\hline
\end{tabular}


Tabel 2. Distribusi usia pasien UG dan UNG.

\begin{tabular}{ccccccccc}
\hline & \multicolumn{2}{c}{2009} & \multicolumn{2}{c}{2010} & \multicolumn{2}{c}{2011} & & \\
\cline { 2 - 7 } Usia & UG & UNG & UG & UNG & UG & UNG & Jumlah & $\%$ \\
\hline $5-14$ & $0(0 \%)$ & $2(2,4 \%)$ & $0(0 \%)$ & $0(0 \%)$ & $0(0 \%)$ & $0(0 \%)$ & 2 & $2,4 \%$ \\
$15-24$ & $3(3,6 \%)$ & $0(0 \%)$ & $6(7,3 \%)$ & $1(1,2 \%)$ & $4(4,9 \%)$ & $2(2,4 \%)$ & 16 & $20 \%$ \\
$25-44$ & $14(17 \%)$ & $6(7,3 \%)$ & $11(13,4 \%)$ & $3(3,6 \%)$ & $10(12,2 \%)$ & $7(8,5 \%)$ & $\mathbf{5 1}$ & $\mathbf{6 2 \%}$ \\
$45-64$ & $3(3,6 \%)$ & $3(3,6 \%)$ & $1(1,2 \%)$ & $1(1,2 \%)$ & $2(2,4 \%)$ & $0(0 \%)$ & 10 & $12 \%$ \\
$\geq 65$ & $1(1,2 \%)$ & $1(1,2 \%)$ & $1(1,2 \%)$ & $0(0 \%)$ & $0(0 \%)$ & $0(0 \%)$ & 3 & $3,6 \%$ \\
\hline Jumlah & 21 & 12 & 19 & 5 & 16 & 9 & 82 & \\
$\%$ & $25,4 \%$ & $14,5 \%$ & $23,1 \%$ & $6 \%$ & $20 \%$ & $11 \%$ & & $100 \%$ \\
\hline
\end{tabular}

Tabel 3. Distribusi pekerjaan pasien UG dan UNG.

\begin{tabular}{ccccccccc}
\hline & \multicolumn{2}{c}{2009} & \multicolumn{2}{c}{2010} & \multicolumn{2}{c}{2011} & & \\
\cline { 2 - 7 } Pekerjaan & UG & UNG & UG & UNG & UG & UNG & Jumlah & $\%$ \\
\hline Pegawai & $12(14,6 \%)$ & $3(3,6 \%)$ & $7(8,5 \%)$ & $3(3,6 \%)$ & $8(10 \%)$ & $5(6,1 \%)$ & $\mathbf{3 8}$ & $\mathbf{4 6 , 4 \%}$ \\
Petani & $0(0 \%)$ & $3(3,6 \%)$ & $1(1,2 \%)$ & $0(0 \%)$ & $1(1,2 \%)$ & $1(1,2 \%)$ & 6 & $7,2 \%$ \\
Pemain bola & $1(1,2 \%)$ & $0(0 \%)$ & $0(0 \%)$ & $0(0 \%)$ & $0(0 \%)$ & $0(0 \%)$ & 1 & $1,2 \%$ \\
Pedagang & $2(2,4 \%)$ & $1(1,2 \%)$ & $1(1,2 \%)$ & $0(0 \%)$ & $1(1,2 \%)$ & $0(0 \%)$ & 5 & $6 \%$ \\
Penyiar radio & $1(1,2 \%)$ & $0(0 \%)$ & $0(0 \%)$ & $0(0 \%)$ & $0(0 \%)$ & $0(0 \%)$ & 1 & $1,2 \%$ \\
Instruktur diving & $1(1,2 \%)$ & $0(0 \%)$ & $0(0 \%)$ & $0(0 \%)$ & $0(0 \%)$ & $0(0 \%)$ & 1 & $1,2 \%$ \\
TNI & $1(1,2 \%)$ & $0(0 \%)$ & $0(0 \%)$ & $0(0 \%)$ & $0(0 \%)$ & $0(0 \%)$ & 1 & $1,2 \%$ \\
Pelajar & $1(1,2 \%)$ & $2(2,4 \%)$ & $3(3,6 \%)$ & $1(1,2 \%)$ & $1(1,2 \%)$ & $2(2,4 \%)$ & 10 & $12 \%$ \\
Supir & $1(1,2 \%)$ & $0(0 \%)$ & $1(1,2 \%)$ & $0(0 \%)$ & $0(0 \%)$ & $0(0 \%)$ & 2 & $2,4 \%$ \\
Buruh & $0(0 \%)$ & $1(1,2 \%)$ & $0(0 \%)$ & $0(0 \%)$ & $1(1,2 \%)$ & $0(0 \%)$ & 2 & $2,4 \%$ \\
Tukang ojek & $0(0 \%)$ & $0(0 \%)$ & $2(2,4 \%)$ & $0(0 \%)$ & $1(1,2 \%)$ & $0(0 \%)$ & 3 & $4 \%$ \\
Polri & $0(0 \%)$ & $0(0 \%)$ & $0(0 \%)$ & $0(0 \%)$ & $1(1,2 \%)$ & $0(0 \%)$ & 1 & $1,2 \%$ \\
Wiraswasta & $0(0 \%)$ & $0(0 \%)$ & $0(0 \%)$ & $0(0 \%)$ & $1(1,2 \%)$ & $1(1,2 \%)$ & 2 & $2,4 \%$ \\
Pelayan & $0(0 \%)$ & $0(0 \%)$ & $0(0 \%)$ & $0(0 \%)$ & $1(1,2 \%)$ & $0(0 \%)$ & 1 & $1,2 \%$ \\
Tidak kerja & $1(1,2 \%)$ & $2(2,4 \%)$ & $4(5 \%)$ & $1(1,2 \%)$ & $0(0 \%)$ & $0(0 \%)$ & 8 & $10 \%$ \\
\hline Jumlah & 21 & 12 & 19 & 5 & 16 & 9 & 82 & \\
\% & $25,4 \%$ & $14,5 \%$ & $23,1 \%$ & $6 \%$ & $20 \%$ & $11 \%$ & & $100 \%$ \\
\hline
\end{tabular}

Distribusi pasien UG dan UNG memperlihatkan kelompok usia terbanyak 2544 tahun, dengan jumlah pasien UG 35 orang dan UNG 16 orang (Tabel 2).

Distribusi berdasarkan pekerjaan memperlihatkan pasien UG dan UNG terbanyak yaitu pegawai (27 orang untuk UG dan 11 orang untuk UNG), diikuti oleh pelajar ( 5 orang untuk UG dan 5 orang untuk UNG) dan tidak kerja (5 orang untuk UG dan 3 orang untuk UNG)
(Tabel 3).

Distribusi berdasarkan pasangan seksual terbanyak untuk UG dan UNG yaitu wanita pekerja seksual (WPS) dengan jumlah 29 orang untuk UG dan 9 orang untuk UNG (Tabel 4).

Distribusi berdasarkan keluhan terbanyak pasien UG dan UNG yaitu nyeri saat berkemih pada pasien UG sejumlah 24 orang $(29,5 \%)$ dan pasien UNG sejumlah 11 orang $(13,3 \%)$ (Tabel 5). 
4 Jurnal e-CliniC (eCl), Volume 1, Nomor 1, Maret 2013, hlm. 1-6

Tabel 4. Distribusi pasangan seksual pasien UG dan UNG.

\begin{tabular}{|c|c|c|c|c|c|c|c|c|}
\hline \multirow{2}{*}{$\begin{array}{c}\text { Pasangan } \\
\text { seksual }\end{array}$} & \multicolumn{2}{|c|}{2009} & \multicolumn{2}{|c|}{2010} & \multicolumn{2}{|c|}{2011} & \multirow[b]{2}{*}{ Jumlah } & \multirow[b]{2}{*}{$\%$} \\
\hline & UG & UNG & UG & UNG & UG & UNG & & \\
\hline Istri & $6(7,3 \%)$ & $6(7,3 \%)$ & $7(8,5 \%)$ & $2(2,4 \%)$ & $1(1,2 \%)$ & $2(2,4 \%)$ & 24 & $29,1 \%$ \\
\hline $\begin{array}{c}\text { Teman } \\
\text { perempuan }\end{array}$ & $4(4,8 \%)$ & $0(0 \%)$ & $0(0 \%)$ & $0(0 \%)$ & $0(0 \%)$ & $0(0 \%)$ & 4 & $5 \%$ \\
\hline WPS & $8(9,7 \%)$ & $2(2,4 \%)$ & $8(9,7 \%)$ & $2(2,4 \%)$ & $13(15,9 \%)$ & $5(6,1 \%)$ & 38 & $46,3 \%$ \\
\hline Pacar & $2(2,4 \%)$ & $1(1,2 \%)$ & $2(2,4 \%)$ & $0(0 \%)$ & $2(2,4 \%)$ & $2(2,4 \%)$ & 9 & $11 \%$ \\
\hline Tidak ada & $1(1,2 \%)$ & $3(3,6 \%)$ & $2(2,4 \%)$ & $1(1,2 \%)$ & $0(0 \%)$ & $0(0 \%)$ & 7 & $8,5 \%$ \\
\hline Jumlah & 21 & 12 & 19 & 5 & 16 & 9 & 82 & \\
\hline$\%$ & $25,4 \%$ & $14,5 \%$ & $23,1 \%$ & $6 \%$ & $20 \%$ & $11 \%$ & & $100 \%$ \\
\hline
\end{tabular}

Tabel 5. Distribusi keluhan pasien UG dan UNG.

\begin{tabular}{|c|c|c|c|c|c|c|c|c|}
\hline \multirow[b]{2}{*}{ Keluhan } & \multicolumn{2}{|c|}{2009} & \multicolumn{2}{|c|}{2010} & \multicolumn{2}{|c|}{2011} & \multirow[b]{2}{*}{ Jumlah } & \multirow[b]{2}{*}{ Persen } \\
\hline & UG & $\overline{\mathrm{UNG}}$ & UG & UNG & $\overline{\mathrm{UG}}$ & UNG & & \\
\hline Nyeri saat berkemih & $7(8,5 \%)$ & $1(1,2 \%)$ & $8(10 \%)$ & $3(3,6 \%)$ & $9(11 \%)$ & $7(8,5 \%)$ & 35 & $42,7 \%$ \\
\hline Sering kencing & $10(12,1 \%)$ & $7(8,5 \%)$ & $4(4,9 \%)$ & $1(1,2 \%)$ & $0(0 \%)$ & $0(0 \%)$ & 22 & $26,8 \%$ \\
\hline Kencing darah pada & & & & & & & & \\
\hline akhir berkemih & $1(1,2 \%)$ & $0(0 \%)$ & $1(1,2 \%)$ & $1(1,2 \%)$ & $1(1,2 \%)$ & $0(0 \%)$ & 4 & $4,9 \%$ \\
\hline Kencing nanah & $3(3,6 \%)$ & $2(2,4 \%)$ & $6(7,3 \%)$ & $0(0 \%)$ & $6(7,3 \%)$ & $1(1,2 \%)$ & 18 & $22 \%$ \\
\hline Gatal & $0(0 \%)$ & $2(2,4 \%)$ & $0(0 \%)$ & $0(0 \%)$ & $0(0 \%)$ & $1(1,2 \%)$ & 3 & $3,6 \%$ \\
\hline Jumlah & 21 & 12 & 19 & 5 & 16 & 9 & 82 & \\
\hline$\%$ & $25,4 \%$ & $14,5 \%$ & $23,1 \%$ & $6 \%$ & $20 \%$ & $11 \%$ & & $100 \%$ \\
\hline
\end{tabular}

\section{BAHASAN}

Berdasarkan hasil penelitian yang telah dilaksanakan pada bulan November 2012 - Desember 2012, maka didapatkan data pada pasien UG dari tahun 2009-2011 (tiga tahun) berjumlah 56 orang $(68,5 \%)$ dan pasien UNG berjumlah 26 orang (31,5\%). Penelitian Jawas dan Murtiastutik tahun 2002-2006 (lima tahun) di RSU Dr. Soetomo Surabaya mendapatkan jumlah pasien baru uretritis gonokokus sebanyak 321 orang $(0,065 \%)$ dari 4880 pasien PMS. ${ }^{10}$ Data ini menunjukkan bahwa jumlah pasien UG di Surabaya masih lebih tinggi dari pada di Manado. Terdapatnya perbedaan ini mungkin disebabkan perbedaan geografi, jumlah penduduk, atau juga karena tidak semua pasien datang berobat ke rumah sakit; ada yang lebih memilih berobat ke dokter praktek umum, puskesmas atau membeli sendiri obat di apotik dengan berbagai alasan seperti rasa malu dan sebagainya.
Pada Tabel 2 kelompok usia terbanyak yaitu 25-44 tahun sebanyak 51 orang (62\%). Hasil penelitian ini sama dengan penelitian Jawas dan Murtiastutik di RSU Dr. Soetomo Surabaya yang terbanyak yaitu usia 25-44 tahun sebanyak 169 orang $(52,6 \%) .{ }^{10}$ Hal ini mungkin disebabkan usia tersebut merupakan usia seksual aktif, sehingga lebih berisiko terinfeksi berbagai infeksi menular seksual.

Pada Tabel 3 jenis pekerjaan pasien yang terbanyak yaitu pegawai dengan jumlah 38 orang $(46,4 \%)$. Hasil penelitian tersebut sama dengan penelitian yang dilakukan oleh Jawas dan Murtiastutik tahun 2002-2006 yang mendapatkan pekerjaan terbanyak ialah pegawai swasta dengan jumlah 134 orang $(41,7 \%)$ dan pegawai negeri sipil 15 orang $(4,7 \%) .{ }^{10}$ Hal ini disebabkan pegawai yang bekerja memiliki cukup waktu luang, penghasilan, dan pergaulan, baik di dalam lingkungan pekerjaan maupun di luar pekerjaan. 
Pada Tabel 4 pasangan seksual terbanyak yaitu WPS dengan jumlah 38 orang $(46,3 \%)$. Hasil penelitian ini sama dengan penelitian yang dilakukan oleh Jawas dan Murtiastutik yang mendapatkan WPS sejumlah 187 orang $(57,6 \%) .{ }^{10} \mathrm{Hal}$ ini mungkin disebabkan WPS termasuk dalam kelompok risiko tinggi tertular dan menularkan infeksi menular seksual (IMS) sehingga laki-laki yang berhubungan seks dengan WPS berisiko tertular IMS, apalagi bila berhubungan seks tanpa menggunakan kondom.

Pada Tabel 5 keluhan yang paling sering dikemukakan oleh pasien yaitu nyeri saat berkemih sejumlah 35 orang $(42,7 \%)$. Hasil ini sama dengan penelitian Jawas dan Murtiastutik yang mendapatkan nyeri saat berkemih pada pasien laki-laki sejumlah 273 orang (85\%). ${ }^{10}$ Pasien laki-laki lebih merasakan keluhan nyeri saat berkemih atau rasa terbakar. Nyeri saat berkemih merupakan gejala khas infeksi saluran kencing bawah seperti sistitis dan uretritis dengan berbagai penyebab, antara lain infeksi menular seksual yang ditularkan melalui aktivitas seksual.

\section{SIMPULAN}

Dalam periode tahun 2009-2011 di SMF Penyakit Kulit dan Kelamin RSUP Prof. Dr. R.D. Kandou Manado pada kasus uretritis dengan penyebab infeksi menular seksual didapatkan kasus UG lebih sering ditemukan daripada UNG. Untuk kedua jenis uretritis, terbanyak pada kelompok usia 25-44 tahun, pekerjaan pegawai, dengan pasangan seksual wanita pekerja seksual, dan keluhan tersering nyeri saat berkemih.

\section{UCAPAN TERIMA KASIH}

Terima kasih ditujukan kepada dr. Nurdjannah J. Niode, SpKK sebagai Dosen Penguji I dan dr. Renate T. Kandou, SpKK sebagai Dosen Penguji II, serta kepada semua pihak yang secara langsung dan tidak langsung telah memberikan gagasan pada penulisan artikel ini.

\section{DAFTAR PUSTAKA}

1. Public Health Agency. Uretritis. 2007 [diakses 17 Januari 2013]; diunduh dari :http://www.phac-aspc.gc.ca/std$\mathrm{mts} / \mathrm{sti} 2006 / \mathrm{pdf} / 04 \mathrm{sti2006g \_ e.pdf}$

2. Indriatmi $\bar{W}$. Data Epidemiologi Kelompok Studi Infeksi Menular Seksual. 2012. Dibawakan pada Simposium Sexually Transmitted Infections A Rising Concern 15-16 September 2012 Semarang.

3. Bignell C. European Guideline on the Diagnosis and Treatment of Gonorrhoea in Adults. International Journal of STD \& AIDS. 2009 [diakses 14 Januari 2013]; diunduh dari http://www.ijsa.rsmjournals.com/20/7/ 453.full.pdf+html.

4. Lina N. Faktor-faktor risiko kejadian gonore. 2011 [diakses 19 Januari 2013]; diunduh dari http://www. journal.unsil.ac.id/jurnal/prosiding/9/9 GO-lina_8.pdf.pdf

5. Bignell C. UK National Guideline for the Management of Gonorrhoea in Adults. Clinical Effectiveness Group British Association for Sexual Health and HIV. 2011 [diakses 18 Januari 2013]; diunduh dari http://www.bashh.org/ documents/3611.

6. Illinois Department of Public Health. NonGonococcal Urethritis. 2008 [diakses 17 Januari 2013]; diunduh dari http://www.idph.state.il.us/public/hb/h bngu.htm.

7. Steven D. Uretritis. University of Mary Land Medical Center. 2010 [diakses 17 Januari 2013]; diunduh dari http://www/umm.edu/altmed/articles/u rethritis-000167.htm.

8. Siregar RS. Gonore. Atlas Berwarna Saripati Penyakit Kulit. Buku Kedokteran Edisi 2. 2005: p.299-300.

9. Bignell C, Unemo M. 2012 European Guideline on the Diagnosis and Treatment of Gonorrhoea in Adults. 2012 [diakses 16 Januari 2013]; diunduh dari http://www.iusti.org/regions /europe/pdf/2012/Gonorrhoea_2012.pdf. 
6 Jurnal e-CliniC (eCl), Volume 1, Nomor 1, Maret 2013, hlm. 1-6

10. Jawas FA, Murtiastutik D. Penderita Gonore di Divisi Penyakit Menular Seksual Unit Rawat Jalan Ilmu Kesehatan Kulit dan Kelamin RSU Dr. Soetomo Surabaya Tahun 2002-2006. Dep/SMF Kesehatan Kulit dan Kelamin. FK UNAIR/RSU Dr. Soetomo Surabaya: 2008 [diakses 17 Januari 2013]; diunduh dari http://www. journal.unair.ac.id/filerPDF/BIKKK_v ol 20 no 3_des2008_Acc_4.pdf. 